\title{
Integrated Framework to Mitigate Risks during Strategy Implementation
}

\author{
${ }^{1}$ Abdelgadir M. Mahmoud, ${ }^{2}$ Omer M. Osman \\ ${ }^{1}$ Senior Lecturer, ${ }^{2} \mathrm{PhD}$ Candidate \\ Razak Faculty of Technology and Informatics \\ Universiti Teknologi Malaysia, Kuala Lumpur, Malaysia
}

\begin{abstract}
In today's competitive business environment, business entities are faced with greater uncertainties (threats and opportunities) as they strive to create value. In the quake of the current global economic crisis, businesses in a bid to stay competitive have taken several crucial measures. However, for companies to keep track of their strategies, achieve their strategic objectives and reduce the impact of uncertainties, appropriate decisions should be made with a solution that reduces the impact of risks. Technical reports from companies showed that there is deviation from their original strategic plan tracks, and they are unable to achieve their strategic objectives. A preliminary study was conducted to identify the factors that lead to inefficiencies during strategic plan implementation. The result of the preliminary study showed that there is lack of risk management, especially information and incentive alignment risks. This research aims to propose a framework that mitigates risks during strategy implementation, through how the key choices made in strategy will either increase or reduce two characteristic types of risk (information and incentive alignment risks). These two types of risk (which are not mentioned in depth in other or past types of risk management categories) are the key inefficiency creators in the strategic planning and decision making that arise because of decision patterns. The proposed framework considers how to question the key decisions and how to turn inefficiencies into opportunities and points of power to create value. The proposed framework also presents essential fundamental concepts and enablers for achieving sustainable performance such as developing organizational capability, creative thinking, innovation, agility, succeeding through people and sustained outstanding results. The framework presents a mechanism to identify and assess the information and incentive alignment risks in the key decisions. The developed framework helps to reinvent desired strategic performance which lies in changing how decisions are made.
\end{abstract}

Index Terms: Agility, information risk, incentive risk, strategy

\section{INTRODUCTION}

The roots of the term risk can be traced back as far as the late middle ages, the modern concept of risk appeared only gradually, with the transition from traditional to modern society. The modern understanding of risk presupposes subjects or institutions, accountable for their actions that make decisions under conditions of apparent uncertainty. Some apparent uncertainties, however, can be measured or quantified probabilistically and are, therefore, more precisely called risks (1). Risk management is a continuous process that is accomplished throughout the life cycle of a system. It is an organized methodology for continuously identifying and measuring the unknowns; developing mitigation options; selecting, planning, and implementing appropriate risk mitigations; and tracking the implementation to ensure successful risk reduction. Effective risk management depends on risk management planning; early identification and analyses of risks; early implementation of corrective actions; continuous monitoring and reassessment; communication, documentation, and coordination (2). Strategy risk relates to risk at the corporate level, and it affects the development and implementation of an organization's strategy (3). Strategy risk is a function of the compatibility of an organization's strategic goals, the business strategies developed by management to achieve those goals, the resources deployed against these goals, and the quality of the implementation (4).

\section{LITERATURE REVIEW}

Enterprise Risk Management (ERM) supports agencies' ability to articulate risks, align and allocate resources, and proactively discuss management and mitigation strategies and activities to better equip agencies to deliver on their goals and objectives and potentially improve stakeholder confidence and trust. Moreover, ERM should operate with the purpose of supporting the mission and vision, integrating existing risk management practices across functional silos and improving strategic planning and decision-making (5).

The environment in which an organization operates has become more complex, more rapidly changing, and more demanding (6). As stated by Drucker (7), we are living in "an age of discontinuitye. It is therefore vital that an organization be aware of the internal and external forces that may shape its future (8). The monitoring, evaluating and disseminating of information from the external environment to key personnel within an organization is known as environmental scanning (9). Hambrick (10) states that environmental scanning refers to the managerial activity of learning about events and trends in the organization's environment. Environmental scanning can yield a number of benefits for decision-makers within the organization, for example, it will help in detecting environmental signals. However, this is only part of the scanning process as assessing its strategic implications requires a forecast of the expected rate of change, or a forecast of the impact of the change (11). In addition, scanning provides managers with information about events and trends in their relevant environments, which facilitates opportunity recognition (12). Also Barringer and Bluedorn (12) state that scanning is a method to reduce uncertainty. Scanning can help managers cope with uncertainty, but only 
if they realize that uncertainty can only be reduced, not eliminated. To assess the organizational environment as one of the main steps in the strategic planning formation process, strategic tools are used. According to Clark (13), strategy tools are concepts, analytical frameworks, techniques and methodologies that assist strategic managers in making informed decisions.

Today, information can no longer be treated as a source of competitive advantage, but a competitive necessity. It penetrates in all aspects of an organization, crosses data processing and information systems department. The information potential can be realized by the means of appropriate management and knowledge of the organizational and cultural aspects (14). Information risk is always present to some extent in every business. Reducing it is most urgent where the inefficiencies it causes are most intense. Getting an assessment of the extent of information inefficiency involves understanding three key properties of the decision that is made with insufficient information. These three key properties of the decision are the consequent of the decision, The degree of reversibility or finality of the decision and the measure of the know unknowns associated with the decisions (14).

Incentive alignment risk arise when the incentive imposed by a business model lead to actions that clash with the boarder interest of a value chain. For most businesses, achieving alignment is a continuous process. While alignment is a state, its definitional opposite - misalignment - is an infinite number of states in a multidimensional space. Thus, a discussion of the alignment process requires both identifying the state of alignment and monitoring the dynamics of misalignment (15). If the decisions made crucial to the strategic direction of the corporate or a business unit with misaligned incentives, the consequent incentive inefficiency is likely to be more harmful and a worthy adversary to take on (16).

\section{METHODOLOGY}

The adopted approach includes qualitative, quantitative and Mixed-method techniques. The instruments used to collect the data in this study are the literature review, the semi- structured interviews, and questionnaires. The outcomes of the literature review and the preliminary study were used as input to identify the factors that lead to inefficiencies in the decision making during strategy implementation, through studying the performance of strategy successful factors in selected business units.

The data collected via semi-structured interviews was used in the preliminary study to evaluate the implementation of the strategy successful factors in selected business units. Questionnaires were used to validate that some business units are suffering from information and incentive alignment risks and evaluate the negative effect of these two types of risk in the decisions making. The reliability coefficient (Cronbach's Alpha) was found to be positive, with the reliability rate based on the Cronbach-Alpha scale ( 0.88 and 0.84 ) for the information and incentive alignment risks data.

In this study, data was analyzed using descriptive and inferential statistics. Descriptive statistics included percentages, frequencies, means, and standard deviations while inferential statistics included regression and correlation analysis. Data processing was undertaken through coding the completed questionnaires, entry into SPSS and then checked for accuracy of data input.

\section{RESULTS AND ANALYSIS}

The results of the preliminary study at selected Business Units revealed that:

1. There were deviations periodically from the strategy plans tracks.

2. There are no risk management procedures during strategy execution.

3. There are no procedures to manage the information and incentive alignment risks.

4. There is no mechanism to manage risks during decision making process.

Questionnaires were used to validate that some business units are suffering from information and incentive alignment risks and evaluate the negative effect of these two types of risk in decisions making. The output of the questionnaires can be summarized in the following main points:

1. Respondents emphasized that the selected business units are affected and suffering of Information and Incentive Alignment Risks.

2. Respondents agreed with the symptoms as factors that lead to inefficiencies in the decision making.

\subsection{PROPOSED FRAMEWORK COMPONENTS}

The proposed framework was formed to promote sustainable success and to provide guidance to keep the strategy plan in its track through managing risks in the decisions. This is realized through a set of three integrated components which comprise the framework. The firs component is the Fundamental Concepts, to underlying principles which are the essential foundation of achieving sustainable and strategy alignment (sustainability). The second component is the Risk Mitigation process, which helps organization to manage risks in decisions, and reinvent decisions aligned with strategy track by converting the fundamental concepts and strategic performance management into practice through innovative decision path. The third component strategic performance management. A dynamic assessment process and powerful management tools to support organizations. It's a multistep process that guides the leadership in designing and revising the strategic performance.

The proposed framework (see Fig. 1) based on continues improvement concept. It is using three integrated components (Fundamental Concepts, Strategy Performance management and Decision risk management process). The framework helps organizations to 
question themselves to invent or keep track of strategy with the attributes to achieve sustainability, drive innovation and improve results.

The proposed framework studying the identification of risks (information and incentive alignment risks symptoms) in the key decisions, then the framework open the path to reinventing desired strategic performance which lies in changing how decisions are made. The proposed framework mainly considers how to question the key decisions and how to identify value destroying points and turn these inefficiencies into opportunities and points of power to unlock new value.

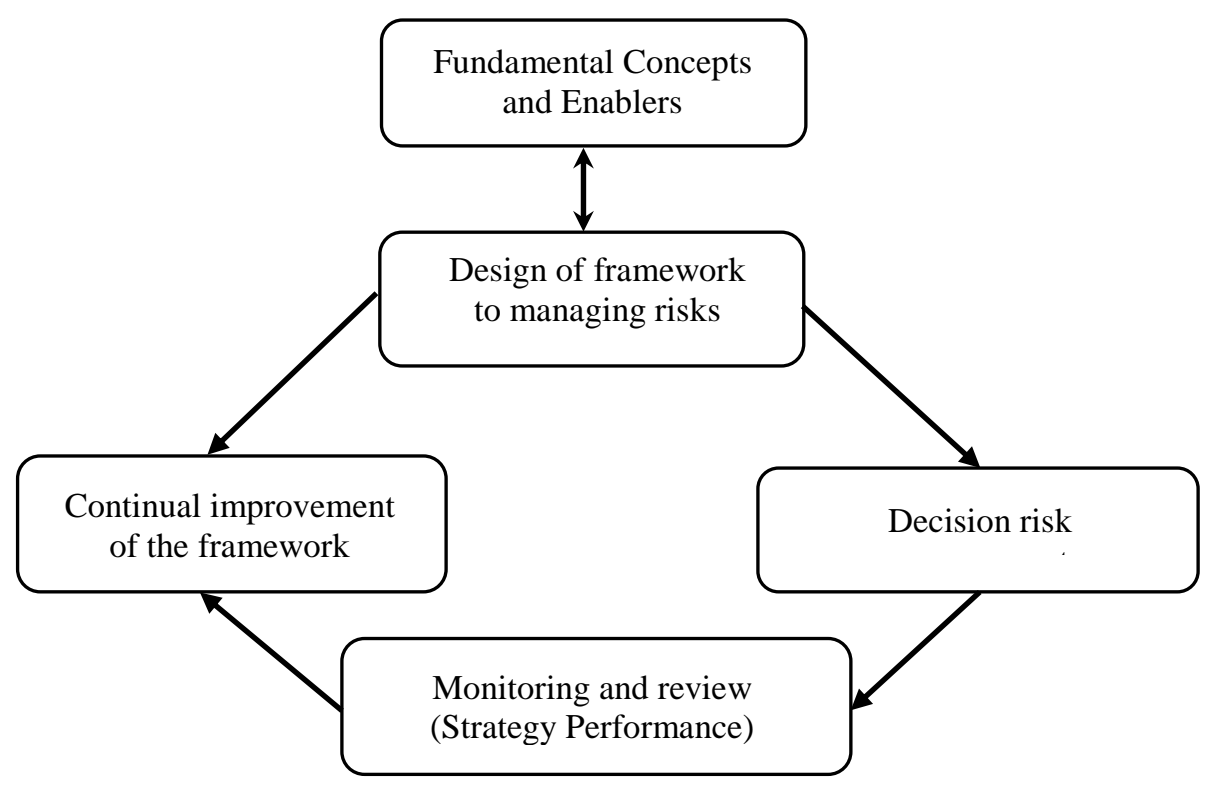

Figure 1 the proposed Framework Components

The strategic performance management provides a structured approach to question the performance of the organization. It combines strategic planning with performance management by creating an organizational structure based on strategies and functions, aligning resources with the structure, addressing human capital and productivity, and establishing performance measures (17).

\subsection{THE FUNDAMENTAL CONCEPTS AND ENABLERS}

These Fundamental Concepts and enablers Contribute in risk mitigation, that it outlines the essential foundation for achieving sustainable performance for the organization. They can be used as the basis to describe the attributes of the framework for the organizational culture. They also serve as a common language for top management and decision makers, these concepts can be summarizing in five enablers (18), which are:

1. Developing Organizational Capability

2. Harnessing Creativity \& Innovation

3. Managing with Agility

4. Succeeding through the People

5. Sustaining Outstanding Results

\subsection{STRATEGIC PERFORMANCE MANAGEMENT}

Strategic Performance Management is a multistep process (Fig. 2) that guides the leadership in designing and revising a system of strategic performance management. It combines strategic planning with performance management by creating an organizational structure based on strategies and functions, aligning resources with the structure, addressing human capital and productivity, and establishing performance measures (19).

\subsection{MANAGING INFORMATION AND INCENTIVE ALIGNMENT RISKS}

The proposed framework considers how to question the key decisions and how to identify value destroying points and turn these inefficiencies into opportunities and points of power to unlock new value during strategy implementation (16). The framework is about mitigating risks through questioning how the key choices made and how will either increase or reduce the two characteristic types of risk (information risk and incentive alignment risk). Mitigating risks is managed through three steps in the proposed framework, which involves: 


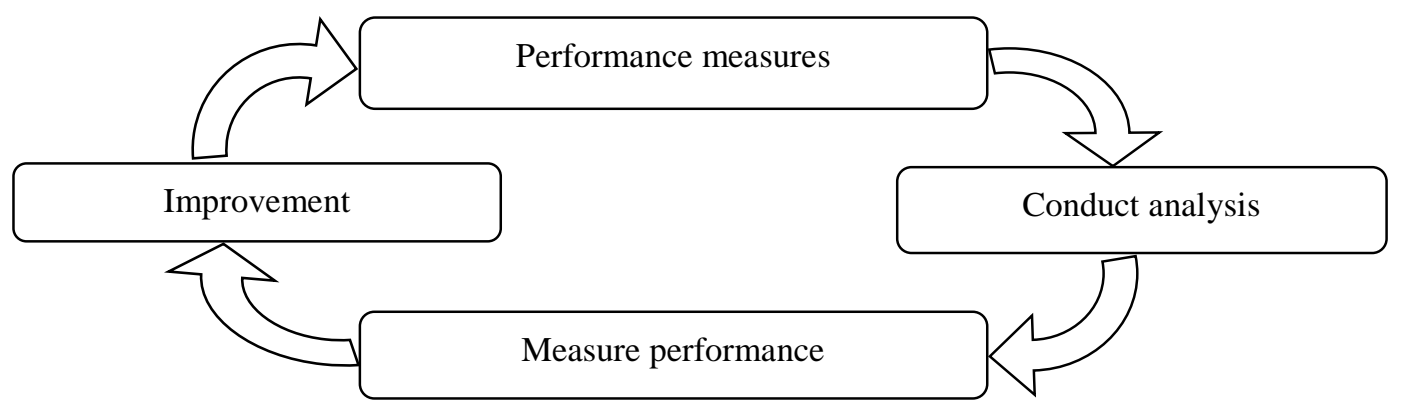

Figure 2 Strategic performance management

\subsubsection{RISK IDENTIFICATION}

Identify and assess inefficiencies in decisions by searching the appearance of signs or symptoms of information and incentive alignment risks, which can help the organization honestly identify value-destroying points and pointed their root-cause inefficiencies.

\subsubsection{RISK ASSESSMENT}

Estimating the consequences of identified risks (16) (information and incentive alignment risks), which are shown in the following points:

1. Incentive alignment risks assessment

2. Information risk assessment

\subsubsection{REINVENT DECISIONS}

The path to reinventing desired strategic performance lies in changing how decisions are made, so decisions are the main factor for inventing and reinventing new strategic decision path. To make this decision formulation the proposed framework chooses four basic types of interventions: changing what decisions strategy involves; when a decision is made; who should make the decision; and why the decision maker makes the decision the way he does.

\subsection{CHANGING WHAT DECISIONS STRATEGY INVOLVES}

Determining what decision to select in designing corporate strategy is usually the dominant driver of their risks and inefficiencies nonetheless; organizations often take these foundational decisions for granted. A few simple rules apply when reinventing the strategy by modifying what it defines as important (16):

1. Balance focus with flexibility: The so-called Pareto principle applied here: 20 percent of products or services account for 80 percent of risks. Eliminate just a few, and the organization will improve excessively.

2. Reduce the number of decisions: It's possible to reduce the number of decisions without reducing products or services offering.

3. Hedge decision against one another: Business risks arising from different decisions seldom rise and fall synchronously. We can complementary decisions to build a portfolio of risks that hold each other in check, balance demand fluctuations and optimize capacity. It can also hedge by pooling resources with other companies.

\subsection{WHEN A DECISION IS MADE}

Determining when to make key business decisions and the order in which they are arranged, relative to one another, is very important to the business and strategic performance and to the value it create. So if the decision pattern modified to change the absolute timing of key decisions and /or the way they interrelate, we can produce powerful business output (16). A few simple rules can help by changing the when of key business decisions:

1. Delay decision as long as possible. If the opportune moment for obtaining information is fixed in time, we can attempt to delay decisions as long as possible to bring them closer to that moment.

2. Change the sequence of decisions. This can be a way to incorporate more information into the process. Some companies have reduced their R\&D risks in this way and others reduced inefficiencies in the way they produce products and services.

3. Split a key decision into phases so as to obtain early information, before the decision is completed. Even when decision sequence can't be changed it may still be able to gather highly useful preliminary information before committing to key decision.

As organizations continue growing in complexity and global reach, decisions in them spread out, creating situations in which the historical decision maker may no longer be best suited to the role. In order to design innovative business models, changing who makes the decision can be an effective-even breaking through strategy (16). Three principles guide this approach:

1. Transfer decision rights to the best-informed decision maker, that will lead to decision

2. Decisions that impose fewer information and incentive-alignment inefficiencies.

3. Transfer decision making to the party best able to tolerate the decision's consequences, that can create value.

4. Move the consequences (costs) of the decision to the party that benefits the most 


\subsection{WHO SHOULD MAKE THE DECISION}

As organizations continue growing in complexity and global reach, decisions in them spread out, creating situations in which the historical decision maker may no longer be best suited to the role. In order to design innovative business models, changing who makes the decision can be an effective-even breaking through strategy (16). Three principles guide this approach:

1. Transfer decision rights to the best-informed decision maker, that will lead to decisions that impose fewer information and incentive-alignment inefficiencies.

2. Transfer decision making to the party best able to tolerate the decision's consequences, that can create value.

3. Move the consequences (costs) of the decision to the party that benefits the most.

\subsection{WHY THE DECISION MAKER MAKES THE DECISION THE WAY HE DOES}

The design of an organization imposes certain goals and incentives on decision makers. Because decision makers are generally rational actors, these factors can powerfully influence the decisions they make. For instance, an organization that cares mainly about near-term profits will make decisions very different from those of an organization that cares most about long-term sustainability. When differently motivated decision makers must collaborate to create value, incentives have to be adjusted so that the parties can pursue their objectives without damaging the value chain. Understanding the respective parties' incentives helps induce decisions that best create value (16).

\subsection{COMMUNICATION AND CONSULTATION}

Communication and consultation with external and internal stakeholders should take place during all stages of the risk management process. Therefore, plans for communication and consultation should be developed at an early stage. These should address issues relating to the risk in decision itself, its causes, its consequences (if known), and the measures being taken to treat it. Effective external and internal communication and consultation should take place to ensure that those accountable for implementing the risk management process and stakeholders understand the basis on which decisions are made, and the reasons why particular actions are required.

\subsection{MONITORING AND REVIEW}

The organization's monitoring and review processes should encompass all aspects of the risk management process for the purposes of:

1. Ensuring that controls are effective and efficient in both design and operation;

2. Obtaining further information to improve risk assessment;

3. Analyzing and learning lessons from events (including near-misses), changes, trends, successes and failures;

4. Detecting changes in the external and internal context, including changes to risk criteria and the risk itself which can require revision of risk treatments and priorities; and

5. Identifying emerging risks.

Progress in implementing risk treatment plans provides a performance measure. The results can be incorporated into the organization's overall performance management, measurement and external and internal reporting activities. The results of monitoring and review should be recorded and externally and internally reported as appropriate, and should also be used as an input to the review of the information and incentive alignment risks management framework. The risk management process is shown in Fig. 3.

\section{CONCLUSION}

Based on the study findings, the study concluded that Information Risk and Incentive Alignment Risk are factors (risks) that affecting business units strategy plan implementation. To reduce the impact of inefficiencies in decision making that arising from information and incentive alignment risk during strategy implementation, the output of the previous studies from objective one and objective two were used as input that used innovation, creative thinking and agility as organizational fundamental concepts to be applied in the business units and also used as enablers to reinvent strategic decisions. Then, for monitoring the strategic performance and the efficiency of the framework and continuous improvement, strategic performance management tools are integrated with the framework components. The developed framework provides guidance to keep the strategy plan in its track through managing risks in decisions. This is realized through a set of three integrated components which make the framework: The Fundamental Concepts and Enablers, The Risk Mitigation Framework and Strategic Performance Management. Using these three integrated components help organizations to question themselves to invent or keep track of strategy with the attributes to achieve sustainability, drive innovation and improve results. 


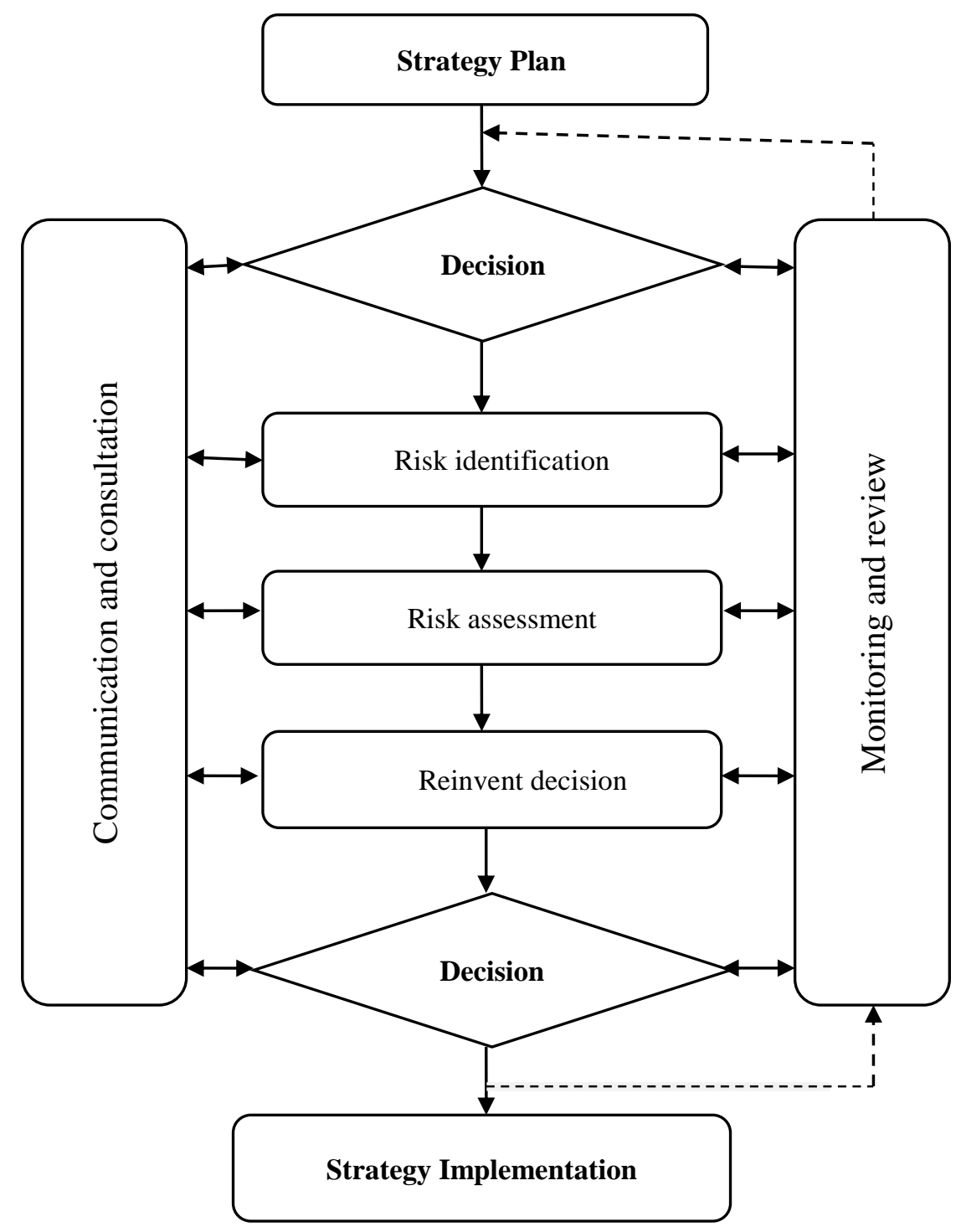

Figure 3 The risk management process

\section{REFERENCES}

[1] Karin Zach Mann. History of Technology. Munich Center for Technology in Society. Technische University, München, Deutsches Museum. 80306 Munich, Germany, 2014.

[2] C. Crouhy. The essentials of risk management. Second edition. US, 2014.

[3] Alexander Roberts. Dr William Wallace. Mr Neil McClure. Strategic Risk Management- Edinburgh Business School Heriot. Watt University Edinburgh. EH14 4AS. United Kingdom. 2012.

[4] Joanne Curtis Taylor. Concepts of strategic risk and managing strategic risk. Janury 2012.

[5] Playbook: Enterprise Risk Management for the U.S. Federal Government, 2016.

[6] Ghosh. Strategic Planning: A Contingency Approach, vol. 16, no. 4, pp. 93-103, AYC, 2.13.

[7] Drucker. The Practice of Management. H\& R, New York, P 2001.

[8] Galloway. Strategic management in public sector research organizations: a critical review, International Journal of Public Sector Management, vol. 3, no. 1, pp. 5-24, ID 2000.

[9] Wheelen and Hunger. Strategic Management. Addison-Wesley. Reading, Mass. JD 2015.

[10] Hambrick. Environmental Scanning and Organizational Strategy, Strategic Management Journal, vol. 3, no. 2, pp. 159-174, 2011.

[11] Barringer and Bluedorn, The Relationship Between Corporate Entrepreneurship and Strategic Management, Strategic Management Journal, vol. 20, pp. 421-444, 1999.

[12] Bluedorn. The interface and convergence of the strategic management and organizational environment domains, Journal of Management, vol. 20, pp. 201-262, 2012.

[13] Clark, Strategic management tools usage: a comparative study Strategic Change, vol. 6, pp. 417-427. 2007.

[14] Maria Stoyanova Todorova. Management Information Systems: Information As A Strategic Resource Impact On Company's Strategy. 3 Nov 2017. 
[15] Christopher M. Scherpereel, Alignment: the duality of decision problems, Northern Arizona University, College of Business Administration, Flagstaff, Arizona, USA,2006.

[16] Karan Girottra And Serguel Netessine. The Risk Driven. Harvard Business Review Press. Boston. 2014.

[17] Suzanne McGilloway. Introduction of a performance management and development system, National College of Ireland. July 2005.

[18] The EFQM Excellence Model 2013, EFQM. Organization. Brussels, Belgium; 2013.

[19] Sam Redding and Allison Layland. Strategic Performance Management, Building State Capacity and Productivity Center. 2015. 